\title{
SELF-PLAGIARISM IN AAAS SCIENCE ARTICLE ABOUT PUBPEER'S PRESIDENT, BRANDON STELL
}

\author{
Jaime A. TEIXEIRA DA SILVA ${ }^{1 *}$
}

\begin{abstract}
Received: February 2020 | Accepted: March 2020| Published August 2020
Please cite this paper as: Teixeira da Silva JA (2019b) Self-plagiarism in AAAS Science article about PubPeer's President, Brandon Stell. Holistica Journal of Business and Public Administration, vol. 11 , iss. 2, pp. 171-178
\end{abstract}

\begin{abstract}
In publishing ethics, self-plagiarism or text recycling is subject to a correction or retraction. This paper examines a high-profile case of ethical exceptionalism in the publishing status quo. Jennifer Couzin-Frankel, a science writer for the magazine Science, published by The American Association for the Advancement of Science (AAAS), was the first reporter to publicly reveal the identity of Brandon Stell, the President of The PubPeer Foundation, which owns PubPeer, a science whistleblower website. The AAAS is a Committee on Publication Ethics (COPE) member publisher. CouzinFrankel published two articles, one of which self-plagiarized (i.e., the use of text written by the same person but not properly cited, or acknowledged) about $25 \%$ of text in the other article. Couzin-Frankel has also employed nested self-citation, which is the citation of a separate part of a paper such as a table or text box, to give the impression of a separate publication. These aspects call into question how strictly information is vetted and edited at AAAS's Science. Despite alerting the AAAS, this heavily self-plagiarized paper has not been corrected or retracted. How then do the $A A A S$ and COPE justify the continued publication of both texts?

Keywords: American Association for the Advancement of Science; ethics; Jennifer Couzin-Frankel; Laura and John Arnold Foundation; opacity
\end{abstract}

\section{Increasing questions about the AAAS-published Science}

The American Association for the Advancement of Science (AAAS) is making strident steps forward in the open access (OA) movement. For example, a major collaboration between the AAAS and The Bill \& Melinda Gates Foundation in which the Gates Foundation paid the AAAS US\$100,000, will ensure that any paper derived from a Gates Foundation project that is submitted to a host of AAAS journals will be OA (AAAS, 2017). However, an article published in the AAAS' premier journal Science by Chawla (2017) formerly a full-time reporter for the science watchdog Retraction Watch (Teixeira da

\footnotetext{
${ }^{1}$ Independent researcher, P. O. Box 7, Miki-cho post office, Ikenobe 3011-2, Kagawa-ken, 7610799, Japan; jaimetex@yahoo.com

* Corresponding author
} 
Silva, 2016) - indicated that the US\$100,000 "deal is likely to affect only a handful of papers", which implies no more than 5 papers in 2017, and thus a cost of US\$20,000 per OA paper. If true, this places a massive premium on OA publishing, making this most likely the most expensive article processing cost (APC) on record registered to date for an OA paper. Both Meagan Phelan, Science Press Package Executive Director at AAAS, and the Gates Foundation, were contacted to clarify this information. Phelan responded as follows: "as the partnership supports more than making Gates-funded research articles open access, one cannot simply divide the amount of the contract award in 2017 by the number of articles we will publish this year. I'll follow up and convey to Chawla." A subsequent request to correct the Chawla statement based on this discordant position between Chawla and the AAAS was made, but the Chawla article was never corrected. This raised the first red flag about quality control and correction of the published literature at Science.

The AAAS also featured prominently in peer review news after it purchased PRE (Peer Review Evaluation) in 2015, developed by Adam Etkin, and described as a "service to help promote transparency and public trust in science" (Pinholster, 2015). The PRE website (http://www.pre-val.org/) describes this service in three keywords: "Integrity. Transparency. Trust." These commercial initiatives suggest that the AAAS, which describes itself as "the world's largest general scientific society", and also as a "nonprofit", leads the way in terms of publishing trends and ethics. One thus can only assume that the AAAS and Science authors, editor and reporters employ the highest level of publication ethics, which is highly likely given that the AAAS is a paying publisher member of the Committee on Publication Ethics (COPE).

For these reasons, academics will be surprised to learn of the discovery of a unique phenomenon, nested self-citation, in which the text box of a larger article was used as a citation "object", even gaining an independent DOI (digital object identifier) and listing at PubMed (Teixeira da Silva, 2017a). One of the authors of the nested self-citation was Jennifer Couzin-Frankel, an established science writer for Science. Papers in Science have been heavily critiqued by Retraction Watch (Retraction Watch, 2017) and at the postpublication peer review and whistle-blower website, PubPeer (https://www.pubpeer.com/) (PubPeer, 2017). This suggests that not all is well, in terms of editorial management and peer review, at the AAAS and Science.

This opinion paper highlights another questionable citation practice by the AAAS' Science. Science has a low (0.34\%) retraction rate (Wray and Anderson, 2018).

\section{Brandon Stell's profiling by Jennifer Couzin-Frankel at AAAS' Science}

Jennifer Couzin-Frankel reached unprecedented fame in 2015 when she revealed the identity of PubPeer's founders (Couzin-Frankel, 2015a, 2015b). That then led to a critical analysis of PubPeer by a plant physiologist, Michael Blatt (Blatt, 2015), which cited Couzin-Frankel (2015a). Couzin-Frankel (2015a) was published on August 31, 2015 while Couzin-Frankel (2015b) was published on September 4, 2015. Both articles have a DOI and are thus citable items, but oddly, only Couzin-Frankel (2015b) is listed at PubMed. 
Curiously, approximately (because no special software was used and the comparison was made manually) $25 \%$ of the Couzin-Frankel (2015a) text was apparently selfplagiarized in Couzin-Frankel (2015b) (Fig. 1). Self-plagiarism is used here to define text written by the same individual in a separate formal publication and reused without any or proper citation to the first original source (Supak-Smocić and Bilić-Zulle 2013; Culley, 2014), also referred to as text recycling (Moskovitz, 2019). The issue of text recycling is highly topical and the subject of retractions, as was recently evidenced in work by prominent Cornell psychologist, Robert Sternberg (McCook, 2018). This phenomenon now raises some additional pertinent questions about Couzin-Frankel, Science, and the AAAS.

\section{Open questions for Science and the AAAS}

The most obvious question arising from this discovery is: is unattributed self-plagiarism (i.e., text recycling) by Couzin-Frankel acceptable in this COPE member journal, Science? Without attempting to review this topic, there appear to be highly contradictory views on the issue of self-plagiarism, even among COPE members and its proponents (Harriman and Patel, 2014; Teixeira da Silva, 2017b). Referring to self-plagiarism, Marcovitch and Barbour (2014) note that "Discussions within COPE and elsewhere have concluded that self-plagiarism in this context is more an issue of copyright than of ethics." The second author of that paper is Virginia Barbour, the former COPE Chair (http://publicationethics.org/about/council/virginia-barbour) from 2012 - May 2017, so the position of COPE is central to this discussion, even more so since 2017 was COPE's $20^{\text {th }}$ anniversary. However, a retraction for self-plagiarism on February 15, 2017 by a Springer Nature journal (Hasan and Abdul-Kareem, 2017), also a COPE member publisher, suggests that the self-plagiarized Couzin-Frankel article should also in fact be retracted, to maintain and display consistency in editorial and ethical policies among COPE members. Inconsistency among COPE member journals and publishers ultimately victimizes authors by sending them mixed signals related to publishing ethics and decreases trust in both COPE and paying COPE member journals and publishers, such as Science and the AAAS (Teixeira da Silva, 2017c).

A request to COPE and to Barbour on February 19, 2017 to offer a firm and clear position by COPE on the issue of self-plagiarism was responded to by Linda Gough, the COPE Administrator, but no clear definition was provided. A second request to COPE's Barbour, Gough and COPE assistant, Iratxe Puebla, on March 8, 2017 to provide a clear and simple, yet quantified definition of what constitutes self-plagiarism was met with silence. In other words, COPE not only failed to offer a formal response and definition of self-plagiarism, including the quantification of textual overlap that constitutes selfplagiarism, its silence reflects serious opacity. A request to Couzin-Frankel and the AAAS to comment on this claim of self-plagiarism was also not answered. Given the centrality of Brandon Stell and PubPeer in the Couzin-Frankel (2015a, 2015b) articles, Stell and his organization were contacted to offer a response and opinion, but no response was ever received, fortifying the notion that there may be actual or perceived ethical exceptionalism (Teixeira da Silva, 2017d) among the publishing elite, and among the 
most vocal pro-ethics science watchdogs (Teixeira da Silva, 2018a). Furthermore, given the close links between Retraction Watch's co-founder (and President of Retraction Watch's parent organization, The Center for Scientific Integrity Inc., or CSI) Ivan Oransky and PRE's founder, Adam Etkin (Etkin and Oransky, 2016), the inclusion of former COPE Chair Elizabeth Wager and Miguel Roig - a supposed specialist on self-plagiarism - on the Retraction Watch Board of Directors (Retraction Watch 2018a), and the special privileged collaboration between the AAAS and Retraction Watch, linked specifically to Etkin's PRE, announced by AAAS' EurekaAlert service (AAAS, 2014), a request was made to Oransky and his organization to respond and offer an opinion and advice. Oransky and Retraction Watch did not respond. Retraction Watch actively monitors Science retractions (Retraction Watch 2018b), as part of its science-shaming or sciencescrutinizing culture (Teixeira da Silva, 2018b).

\section{Conclusions}

Publishing ethics has evolved to establish a fairly rigorous set of ethical guidelines, by which authors are meant to abide. These are, to some extent, the moral codes of publishing, and when they are used, they serve to appreciate and delineate what is right from wrong (Sliwa, 2017). As indicated above, the AAAS advertises the three pillars of its commercial product PRE as integrity, transparency, and trust. However, the AAAS and its science writer Couzin-Frankel have displayed opacity, and questionable publishing integrity in the form of self-plagiarism. According to Miguel Roig, who is one of the Directors of Retraction Watch's parent organization, the CSI, self-plagiarism is unethical, or highly questionable, noting that "the key component of this malpractice is that the new paper makes no reference to the previous publication" (Roig, 2010), as occurs in Couzin-Frankel (2015b), which does not implicitly cite Couzin-Frankel (2015a), or even recognize its existence. Garfinkel (2015) states at the AAAS that the issue is not that clear. If then, the self-plagiarized Couzin-Frankel (2015b) article is not retracted, then this places the ethical position of Retraction Watch and the AAAS, who became official news partners as of August 2016 (Oransky, 2016), in direct contrast and at logger-heads. Consequently, how can academia trust a publisher like the AAAS in such circumstances?

In addition, closely related proponents such as Ivan Oransky and Retraction Watch, as well as Brandon Stell and PubPeer, all failed to offer a formal response for commentary while COPE assumed no position, simply indicating the following: "You are welcome to search our site for our resources. Please see our website here: http://publicationethics.org/". This indicates that COPE has no crystal clear policy on self-plagiarism, including on the quantification of self-plagiarism, textual or otherwise, that would constitute a breach of publishing ethics. This fortifies COPE's loss of moral compass (Teixeira da Silva, 2019a). More importantly, anonymous comments highlighting this textual overlap posted to PubPeer were not approved by the PubPeer moderators, both in 2017 and again in 2020, suggesting a highly biased, and thus manipulated and hypocritical (to suit their own needs while avoiding criticism of their own work or of work related to them) post-publication platform. There are concerns that comment moderation by and at PubPeer but moderators of unknown identity may 
HOLISTICA Vol 11, Issue 2, 2020, pp.171-178

represent a form of comment manipulation, infringing upon author's (i.e., commentators') rights and freedom of speech, and calling into question the issue of comment ownership on this anonymous platform (Teixeira da Silva, 2018c, 2018d, 2018e, 2019b).

How then, can the academic community trust these science watchdogs, ethics organization (COPE), and publisher (AAAS) when they are unwilling to engage with the public and with academia while espousing ethics and transparency as their core values, and demanding such values of the academic community, punishing them with profiling and shaming when responses from academics are not forthcoming? Journalists can, on occasion, be released from their duty as writers, as occurred with Nic Cavell, who was fired from WIRED after plagiarism was detected in four of his articles (Mullin, 2016).

Figure 1 Select excerpts from Couzin-Frankel (2015a, 2015b) articles showing selfplagiarism (non-attribution to the source; lack of direct quotation marks). The articles describe the emergence from anonymity of the PubPeer Foundation President, Brandon Stell, and the rise to whistle-blower status of this blog. All screen-shots used under the fair-use agreement for post-publication peer review (Teixeira da Silva, 2015). A comparison was posted anonymously in 2017 and then again in 2020 to the PubPeer entries indicated in the reference list. 


\section{Couzin-Frankel 2015a}

After 3 years in the shadows, the anonymous founder of a popular and controversial website that allows users to critique published research has revealed himself. "I'm a bit nervous ... I wouldn't call myself a risk-taker," admits Brandon Stell, a 41-year-old neuroscientist and the main force behind PubPeer, which has become an influential outlet for identifying flawed-and sometimes fraudulent -studies.
Couzin-Frankel 2015b

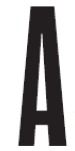

fter 3 years in the shadows, the anonymous founder of a popular and controversial website that allows users to critique published research revealed himself this week. "I'm a bit nervous ... I wouldn't call myself a risk-taker," admits Brandon Stell, a 41-yearold neuroscientist and the main force behind PubPeer. The site has become an influential outlet for identifying flawed, and sometimes fraudulent, studies,
Richard Smith worked in his lab in Paris for a few months as a graduate student. George Smith is a web developer who handles the site's technical elements.
Stell says Richard Smith worked with him in Paris for several months as a graduate student. George Smith is a web developer who built the site and handles its technical elements.
He used a

temporary phone number for interviews and an anonymous email account. "I don't want it to impact my scientific life or my personal life," he explained then, though he also conceded, "I think it's going to be very hard to stay anonymous forever."
He used a temporary phone number and an anonymous email. He didn't want PubPeer “to impact my scientific life or my personal life," he said at the time. But he also conceded that it was "going to be very hard to stay anonymous forever."

\section{a cancer}

researcher at Wayne State University in Detroit, Michigan, filed suit against anonymous commenters on PubPeer, alleging their negative appraisals of his work had resulted in a university rescinding a job offer. PubPeer's lawyers are currently appealing a judge's ruling that it must hand over identifying information from one anonymous poster. a cancer researcher at Wayne State University in Detroit, Michigan, filed suit against some anonymous users, alleging that their negative comments cost him a job offer. PubPeer's lawyers are currently appealing a judge's order to hand over information on one anonymous commenter.
"I think ethics may be a part of" Stell's motivation for creating PubPeer, Llano says. "If knowledge is not transmitted directly and with real honesty, then there is not a basis for science ... This is his way of reacting, of saying, 'OK, I will do something about this."
"I think ethics may be a part of" Stell's motivation for creating PubPeer, agrees Isabel Llano,

"If knowledge is not transmitted directly and with real honesty, then there is not a basis for science. ... This is his way of reacting, of saying: 'OK, I will do something about this."”

\section{Conflicts of interest/disclaimer}

The author and his work have been profiled by PubPeer and by Retraction Watch. The author has used PubPeer and Retraction Watch as a signed, registered commentator, and anonymously. The author has also written several commentaries on these platforms and science watchdogs, as well as commentaries critical of COPE. The author declares no other apparent conflicts of interest.

\section{References}

AAAS (2014) Retraction Watch and PRE partner to improve scholarly publishing practices. https://www.eurekalert.org/pub_releases/2014-09/joba-rwa091114.php (last accessed: March 11, 2020) 
HOLISTICA Vol 11, Issue 2, 2020, pp.171-178

AAAS (2017) AAAS and Gates Foundation partnership announcement. AAAS forms partnership to expand access to high-quality scientific publishing. http://www.sciencemag.org/about/aaas-and-gates-foundation-partnershipannouncement (last accessed: March 11, 2020)

Blatt MR (2015) Vigilante science. Plant Physiology 169(2): 907-909. DOI: 10.1104/pp.15.01443

Chawla DS (2017) Gates Foundation strikes deal to allow its researchers to publish in Science journals. DOI: 10.1126/science.aal0767

Couzin-Frankel J (2015a) PubPeer's secret is out: Founder of controversial website reveals himself. Science DOI: 10.1126/science.aad1691; https://www.pubpeer.com/publications/139799228DD44E9F5129462C843AE1

Couzin-Frankel J (2015b) PubPeer co-founder reveals identity - and new plans. Science 349(6252): 1036 DOI: 10.1126/science.349.6252.1036; https://www.pubpeer.com/publications/505FBF801E2E7F3B0BC1147116A657

Culley, T.M. (2014) APPS's stance on self-plagiarism: Just say no. Applications in Plant Science 2(7), pii: apps.1400055. DOI: 10.3732/apps.1400055

Etkin A, Oransky I (2016) Dopey dupe retractions: How publisher error hurts researchers. Editorial Office News 9(11): p. 12. DOI: 10.18243/eon/2016.9.11.2

Garfinkel MS (2015) A fresh look at self-plagiarism. http://www.aaas.org/news/fresh-look-selfplagiarism (last accessed: March 11, 2020)

Harriman S, Patel J (2014) Text recycling: acceptable or misconduct? BMC Medicine 12:148. DOI: 10.1186/s12916-014-0148-8

Hasan H, Abdul-Kareem S (2017) Retraction Note to: Human-computer interaction using visionbased hand gesture recognition systems: a survey. Neural Computing and Applications 28(4): 849. DOI: 10.1007/s00521-017-2867-1

Marcovitch H, Barbour V (2014) Whose words in the textbook? Anesthesia \& Analgesia 118(1): 34. DOI: 10.1213 /ANE.0b013e3182a5c5ef

McCook, A. (2018) Journal says it will correct three papers by prominent psychologist for duplication. https://retractionwatch.com/2018/05/16/journal-says-it-will-correct-threepapers-by-prominent-psychologist-for-duplication/ (last accessed: March 11, 2020)

Moskovitz, C. (2019) Text recycling in scientific writing. Science and Engineering Ethics 25(3): 813851. DOI: $10.1007 /$ s11948-017-0008-y

Mullin B (2016) WIRED fires reporting fellow for plagiarism. http://www.poynter.org/2016/wiredfires-reporter-for-plagiarism/398571/ (last accessed: March 11, 2020)

Oransky I (2016) Happy sixth anniversary, Retraction Watch! Here's to a new partnership with Science. http://retractionwatch.com/2016/08/03/happy-sixth-anniversary-retractionwatch-heres-to-a-new-partnership-with-science/ (last accessed: March 11, 2020)

Pinholster G (2015) AAAS, publisher of Science, acquires Peer Review Evaluation (PRE) service to help promote transparency and public trust in science. http://www.aaas.org/news/aaaspublisher-science-acquires-peer-review-evaluation-pre-service-help-promotetransparency (last accessed: March 11, 2020)

PubPeer (2017) Science. https://www.pubpeer.com/journals/Science (last accessed: March 11, 2020)

Retraction Watch (2018a) Board of directors. https://retractionwatch.com/the-center-forscientific-integrity/board-of-directors/ (last accessed: March 11, 2020)

Retraction Watch (2018b) Science. http://retractionwatch.com/category/by-journal/sciencejournal/ and http://retractionwatch.com/category/by-journal/science-journal-retractions/ (last accessed: March 11, 2020) 
Roig M (2010) Plagiarism and self-plagiarism: What every author should know. Biochemia Medica 20(3):295-300. DOI: 10.11613/BM.2010.037

Sliwa, P. (2017) Moral understanding as knowing right from wrong. Ethics 127(3): 521-552. DOI: $10.1086 / 690011$

Supak-Smocić, V., Bilić-Zulle, L. (2013). How do we handle self-plagiarism in submitted manuscripts? Biochemica Medica 23(2): 150-153. DOI: 10.11613/BM.2013.019

Teixeira da Silva JA (2015) Fair use in post-publication peer review. Journal of Educational and Social Research 5(3): 13. DOI: 10.5901/jesr.2015.v5n3p13

Teixeira da Silva JA (2016) Science watchdogs. Academic Journal of Interdisciplinary Studies 5(3): 13-15. DOI: 10.5901/ajis.2016.v5n3p13

Teixeira da Silva JA (2017a) Nested self-citation: the citation of a paper's least divisible unit. Scientometrics 111(1): 547-552. DOI: 10.1007/s11192-017-2249-6

Teixeira da Silva JA (2017b) Copy-paste: 2-click step to success and productivity that underlies self-plagiarism. Science and Engineering Ethics 23(3): 943-944. DOI: 10.1007/s11948-0169804-z

Teixeira da Silva JA (2017c) COPE requires greater consistency and accountability. Mediterranean Journal of Social Sciences 8(1): 11-13. DOI: 10.5901/mjss.2017.v8n1p

Teixeira da Silva JA (2017d) Ethical exceptionalism: can publishing rules be manipulated to give the impression of ethical publishing? Bangladesh Journal of Medical Science 16(4): 610614. DOI: $10.3329 /$ bjms.v16i4.33623

Teixeira da Silva JA (2018a) The opacity of The PubPeer Foundation: what PubPeer's "About" page tells us. Online Information Review 42(2): 282-287. DOI: 10.1108/OIR-06-2017-0191

Teixeira da Silva JA (2018b) Freedom of speech and public shaming by the science watchdogs. Journal of Advocacy, Research and Education 5(1): 11-22.

Teixeira da Silva JA (2018c) The issue of comment ownership and copright at PubPeer. Journal of Educational Media \& Library Sciences 55(2): 181-191. DOI: 10.6120/JoEMLS.201807_55(2).e001.BC.BE

Teixeira da Silva JA (2018d) Reflection on the Fazlul Sarkar vs. PubPeer ("John Doe") case. Science and Engineering Ethics 24(1): 323-325. DOI: 10.1007/s11948-016-9863-1

Teixeira da Silva JA (2018e) The issue of comment ownership and copright at PubPeer. Journal of Educational Media \& Library Sciences 55(2): 181-191. DOI: 10.6120/JoEMLS.201807_55(2).e001.BC.BE

Teixeira da Silva JA (2019a) Debunking the loss of the Committee on Publication Ethics (COPE) moral compass: conspiracy theory, or genuine cause for concern? Eubios Journal of Asian and International Bioethics 29(3): 99-109.

Teixeira da Silva JA (2019b) Comment moderation and freedom of speech at PubPeer: challenges and issues. Journal of Advocacy, Research and Education 6(3): 4-10.

Wray KB, Anderson LE (2018) Retractions in Science. Scientometrics 117(3): 2009-2019. DOI: 10.1007/s11192-018-2922-4 